February 2005 - NREL/CP-520-37390

\title{
Control of Moisture Ingress into Photovoltaic Modules
}

\author{
M.D. Kempe
}

Prepared for the $31^{\text {st }}$ IEEE Photovoltaics Specialists Conference and Exhibition

Lake Buena Vista, Florida

January 3-7, 2005

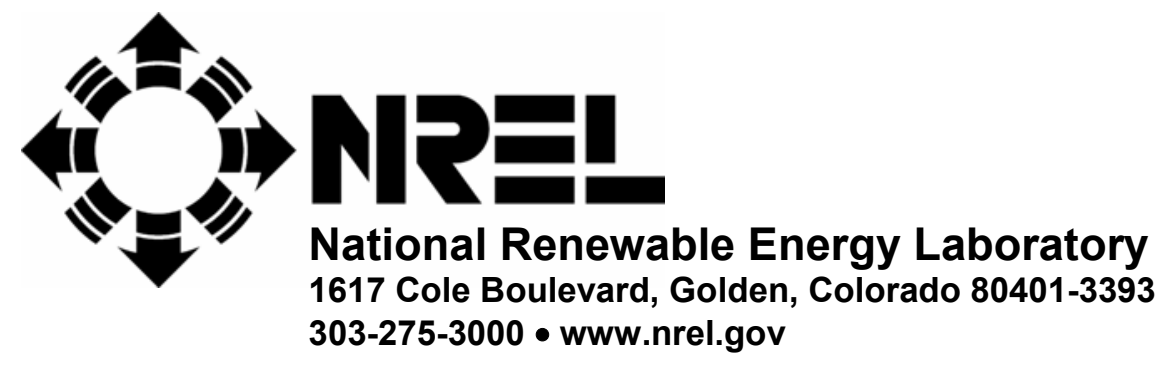

Operated for the U.S. Department of Energy

Office of Energy Efficiency and Renewable Energy

by Midwest Research Institute $\bullet$ Battelle

Contract No. DE-AC36-99-G010337 


\section{NOTICE}

The submitted manuscript has been offered by an employee of the Midwest Research Institute (MRI), a contractor of the US Government under Contract No. DE-AC36-99G010337. Accordingly, the US Government and MRI retain a nonexclusive royalty-free license to publish or reproduce the published form of this contribution, or allow others to do so, for US Government purposes.

This report was prepared as an account of work sponsored by an agency of the United States government. Neither the United States government nor any agency thereof, nor any of their employees, makes any warranty, express or implied, or assumes any legal liability or responsibility for the accuracy, completeness, or usefulness of any information, apparatus, product, or process disclosed, or represents that its use would not infringe privately owned rights. Reference herein to any specific commercial product, process, or service by trade name, trademark, manufacturer, or otherwise does not necessarily constitute or imply its endorsement, recommendation, or favoring by the United States government or any agency thereof. The views and opinions of authors expressed herein do not necessarily state or reflect those of the United States government or any agency thereof.

Available electronically at http://www.osti.gov/bridge

Available for a processing fee to U.S. Department of Energy and its contractors, in paper, from:

U.S. Department of Energy

Office of Scientific and Technical Information

P.O. Box 62

Oak Ridge, TN 37831-0062

phone: 865.576 .8401

fax: 865.576.5728

email: mailto:reports@adonis.osti.gov

Available for sale to the public, in paper, from:

U.S. Department of Commerce

National Technical Information Service

5285 Port Royal Road

Springfield, VA 22161

phone: 800.553 .6847

fax: 703.605.6900

email: orders@ntis.fedworld.gov

online ordering: http://www.ntis.gov/ordering.htm 


\title{
CONTROL OF MOISTURE INGRESS INTO PHOTOVOLTAIC MODULES
}

\author{
Michael D. Kempe \\ National Renewable Energy Laboratory \\ 1617 Cole Boulevard, Golden CO 80401
}

\begin{abstract}
During long-term exposure of photovoltaic modules to environmental stress, the ingress of water into the module is correlated with decreased performance. By using diffusivity measurements for water through encapsulants such as ethylene vinyl acetate (EVA), we have modeled moisture ingress using a finite-element analysis with atmospheric data from various locations such as Miami, Florida. This analysis shows that because of the high diffusivity of EVA, even an impermeable glass back-sheet alone is incapable of preventing significant moisture ingress from the edges for a 20-year lifecycle. This result has led us to investigate ways to protect module from the moisture through the use of different encapsulating chemistries and materials.
\end{abstract}

\section{INTRODUCTION}

The ingress of moisture into photovoltaic (PV) modules has been correlated with increased failure rates, especially in hot and humid climates such as Miami, Florida. The first step toward understanding this failure mechanism is to determine how long it takes a module to approach equilibrium with the water in the external environment. To do this, the diffusivity and water absorption capacity of ethylene vinyl acetate (EVA) was measured to obtain the necessary information to model water-ingress rates. This allowed one-dimensional (1-D) finite-element analysis to be performed using meteorological data to determine the transient water content within the module for the case of a breathable back-sheet and for a double-glass laminate.

\section{EXPERIMENTAL}

\section{Diffusivity and solubility measurements}

The transient water-vapor transmission rate (WVTR) through a 2.84-mm-thick EVA membrane was measured using a Mocon Permatron- $W^{\circledR} 3 / 31$. Passing dry nitrogen across both sides of the membrane dried the sample, and the measurement was started when liquid water was introduced to one side (see Fig. 1a). If one assumes that the diffusivity obeys Fick's law (diffusivity is independent of concentration), then the transient WVTR can be described as:

$$
\operatorname{WVTR}(t)=\frac{D C_{S}}{l}\left[1+2 \sum_{n=1}^{\infty}(-1)^{n} e^{\left(\frac{-D n^{2} \pi^{2} t}{l^{2}}\right)}\right],
$$

where $D$ is the diffusivity, $C_{s}$ is the saturation concentration, $t$ is time, and $I$ is the membrane thickness [1]. A small shift of $\sim 80 \mathrm{~s}$ was needed for the time axis prior to fitting Eq. 1 to the data. The diffusivity is determined first by the time required to reach steady state, and then the water-saturation concentration is determined by the steady-state WVTR (see Fig. 1b).
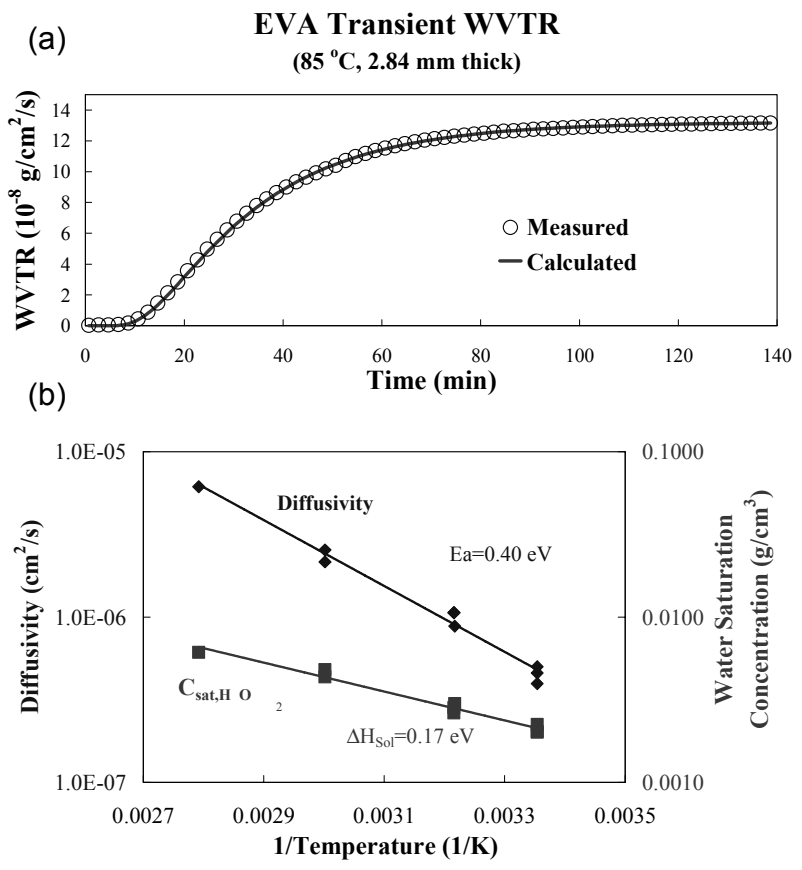

Fig. 1. (a) Sample WVTR measurement used to measure diffusivity. The solid line was calculated using Eq. 1. (b) Plot of water diffusivity and solubility in EVA.

The diffusivity and solubility for other polymeric materials was also measured to evaluate their potential use in PV modules (see Fig. 2). All of these materials (except for BRP-C, which contains considerable filler) were found to have a transient WVTR that was well described by Eq. 1, indicating that their diffusivity is Fickian. For BRP-C, the 
diffusivity values are only effective diffusivities that are best applied at long times.

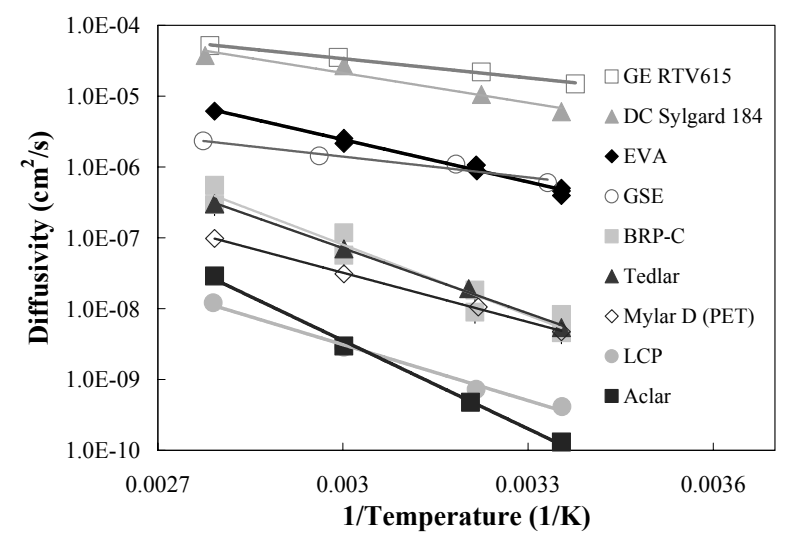

Fig. 2. Diffusivity measurements for several polymers. GE RTV615 and DC Sylgard 184 are both polydimethyl silicones manufactured by General Electric and Dow Corning, respectively. GSE is an experimental film provided by Global Solar. BRP-C is an experimental encapsulant from BRP Manufacturing. LCP is a liquid crystal polymer.

It was found that EVA has a relatively high diffusivity that is only exceeded by silicones. It should also be noted that the diffusivity of the different materials varies by orders of magnitude and that consequently the time for moisture ingress also varies by orders of magnitude.

\section{Determination of module exposure from meteorologi- cal data}

Meteorological data for Miami, Florida, for 2002 were obtained from Atlas Weather Services under a subcontract with the National Renewable Energy Laboratory (NREL). Data for Golden, Colorado, were measured at NREL. Because the Miami data did not include module temperature, this had to be estimated using heat-transfer equations, as outlined by Myers [2] The data from NREL included module temperature and were used to validate the heart transfer calculations and make slight modification to some of the model parameters for improved accuracy.

The Miami data were obtained in 10-min increments, with occasional missing data points. When this occurred, the data were interpolated between adjacent points. For large sections of missing data, points were substituted from the previous day.

\section{RESULTS AND DISCUSSION}

\section{Moisture ingress into a breathable back-sheet}

The moisture ingress through a breathable backsheet can be modeled as a one-dimensional (1-D) diffusion problem where the inner boundary (the PV device) is impermeable, the outer exposed surface is in equilibrium with the environment, and the elements at the interface between the EVA and the back-sheet are assumed to be in equilibrium (see Fig. 3). These assumptions were then used in a finite-element analysis. For each time step, the temperature of the module (along with the diffusivity and solubility) and the outer surface concentration are changed, and the implicit method is used to compute the concentration profile for the next time step. In this model, 49 spatial elements were used for the back-sheet and 36 spatial elements were used for the EVA layer.

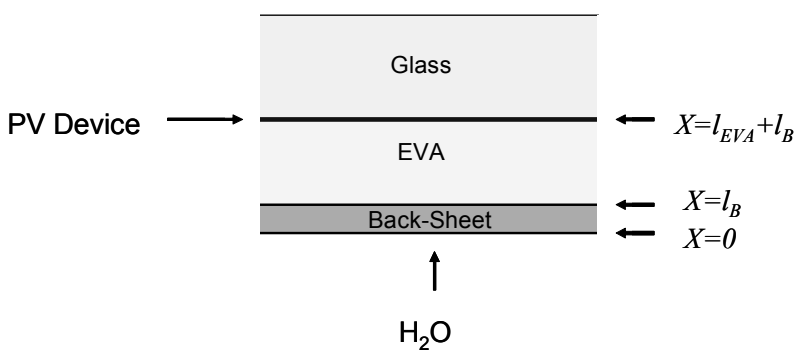

Fig. 3. Schematic of model used for a module with a breathable back-sheet.

A module with a breathable back-sheet was modeled by starting with an initially dry EVA encapsulant (see Fig. 4) with a thickness of $0.46-\mathrm{mm}$ and a composite backsheet consisting of $\operatorname{Tedlar}^{\mathrm{TM}}(0.038 \mathrm{~mm}) /$ polyethylene terepthalate $(0.051-\mathrm{mm})$ / EVA $(0.10-\mathrm{mm})$. Using an effective diffusivity and solubility for the composite backsheet, it takes approximately 24 to $36 \mathrm{~h}$ for the water content to reach equilibrium.

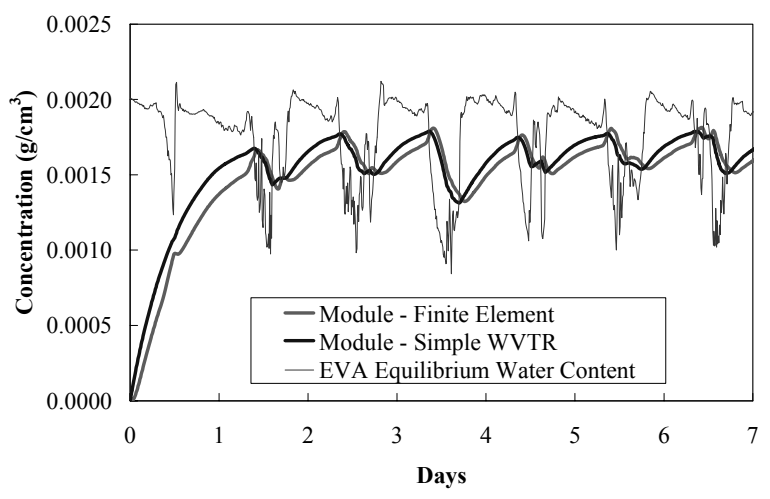

Fig. 4. Transient moisture content at the cell interface calculated using data from Miami, Florida, for 2002. The back-sheet was modeled using an effective diffusivity and solubility measured on a composite film of Tedlar $^{\mathrm{TM}}(0.038$ $\mathrm{mm})$ / polyethyleneterepthalate $(0.051 \mathrm{~mm})$ / EVA $(0.10$ $\mathrm{mm}$ ). The EVA encapsulant was modeled as $0.46 \mathrm{~mm}$ thick. The simple WVTR line was modeled using Eq. 2.

Rather than using a complicated finite-element analysis to determine the equilibration time, a simpler model equation can be assumed [3]: 


$$
\frac{d C_{E}}{d t}=\frac{W V T R_{B, \text { Max }}}{C_{E, \text { Sat. }} l_{E}}\left[C_{B}(0)-C_{B}\left(l_{B}\right)\right]
$$

where the subscripts Sat, $B$ and $E$ indicate conditions at saturation, in the back-sheet, and encapsulant, respectively, and $W V T R_{B, M a x}$ is the rate with $100 \%$ and $0 \%$ relative humidity $(\mathrm{RH})$ on opposite sides of the back-sheet. To use this model, one assumes that the encapsulant diffusivity is much greater than the back-sheet diffusivity $\left(D_{E}>>D_{B}\right)$, that the concentration profile in the back-sheet is linear, and that the concentration in the encapsulant is independent of position. To use Eq. 2 with the meteorological data from Miami, one can simply estimate a small loss or gain of water for each time step. Figure 4 demonstrates that both methods produce qualitatively the same result, with the finite-element model predicting a small time lag.

Integration of Eq. 2 (assuming a constant temperature and $\mathrm{RH}$ as will be justified in the next section) indicates that the equilibration follows an exponential decay and that the half-time (the time to reach half the equilibrium value) for this process is,

$$
\tau_{1 / 2}=0.693 \frac{C_{\text {Sat, }} l_{E}}{W V T R_{B, \text { Max }}} .
$$

This equation suggests that for a back-sheet to have an equilibration half-time of 20 years, a WVTR $R_{B, \operatorname{Max}}$ of $10^{-4}$ $\left(\mathrm{g} / \mathrm{m}^{2} /\right.$ day $)$ is necessary at $27^{\circ} \mathrm{C}$. Because most backsheets used with PV devices have a $W V T R_{B, M a x}$ that is typically greater than $10^{-1}\left(\mathrm{~g} / \mathrm{m}^{2} /\right.$ day), all these systems are at equilibrium. It is not until WVTR $R_{B, M a x} \sim 10^{-6}\left(\mathrm{~g} / \mathrm{m}^{2} /\right.$ day $)$ that one can neglect water permeation through a backsheet.

\section{Moisture ingress in double-glass laminates}

For the case where the back-sheet is an impermeable barrier (such as glass), water can still enter through the sides of the module. This process was modeled using a 1$\mathrm{D}$ explicit finite-element analysis consisting of 55 spatial elements using meteorological data for Miami, Florida, for 2002 (see dotted lines in Fig. 5). The outer edge of the module was assumed to be at equilibrium with the surroundings, and because of symmetry the center of the module is modeled as an impermeable barrier. Ignoring the 2-D nature of the module is valid for short times (relative to the diffusion rate) or for long and narrow module shapes.

In this 1-D model, an analytical solution can be obtained starting with an initially dry module if one assumes a constant temperature and external $\mathrm{RH}$

$$
C(x, t)=C_{S}+\frac{4\left(C_{s}\right)}{\pi} \sum_{m=0}^{\infty} \frac{1}{2 m+1} \sin \left[\frac{(2 m+1) \pi x}{l}\right] e^{\left(-\frac{D(2 m+1)^{2} \pi^{2} t}{l^{2}}\right)} .
$$

At distances greater than $\sim 4 \mathrm{~cm}$ from the module edge, the seasonal fluctuations are damped out and Eq. 4 provides an accurate representation of the finite-element model when $\mathrm{T}=26.7^{\circ} \mathrm{C}$ and $\mathrm{RH}=71 \%$ which correspond to an average temperature and an average water concentration. The high diffusivity of EVA allows for moisture to reach the center of a module with a width of $40 \mathrm{~cm}$ in about 2 years (see Fig. 5).

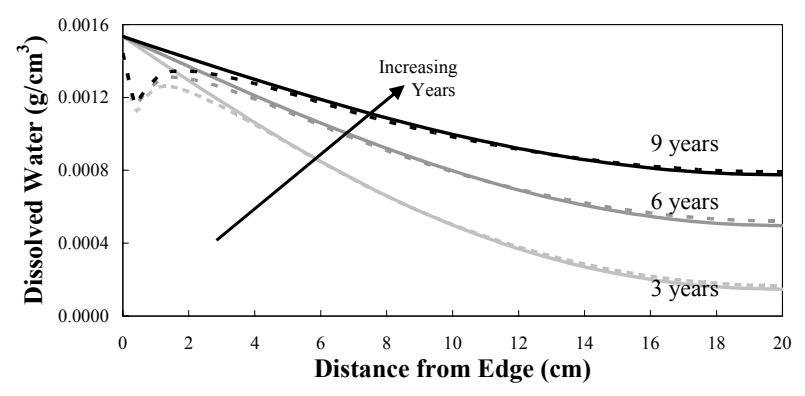

Fig. 5. Model of moisture ingress in double-glass laminate construction using EVA. Dotted lines are for the finiteelement model. Solid lines are for Eq. 4 using $\mathrm{T}=26.7^{\circ} \mathrm{C}$ and $\mathrm{RH}=71 \%$.

This model demonstrates that by using environmental conditions of $\mathrm{T}=26.7^{\circ} \mathrm{C}$ and $\mathrm{RH}=71 \%$, one can approximate conditions of Miami, Florida, and obtain estimates for the time scale of moisture ingress. Evaluation and inspection of Eq. 4 indicates that the half-time for moisture ingress into the center of the module is given by

$$
\tau_{1 / 2}=0.0947 \frac{l^{2}}{D}
$$

Therefore, to keep water out of the module center for 30 years would require a module that is 3 to 4 times larger or a diffusivity that is more than 10 to 20 times smaller. For a square module, the prefactor for the equilibration time would be 0.0593 instead of 0.0947 , indicating an approximately $38 \%$ increase in the water-ingress rate (see Table 1). One should also consider that this model neglects moisture ingress due to diffusion along surfaces and through the junction box, or due to delamination and capillary action. Diffusion of water from the sides is significant over the lifetime of a module unless a module is a few meters across.

\begin{tabular}{|l|l|l|}
\hline \multirow{2}{*}{ Encapsulant Material } & \multicolumn{2}{|c|}{$\tau_{1 / 2}$} \\
\cline { 2 - 3 } & $1=10 \mathrm{~cm}$ & $1=50 \mathrm{~cm}$ \\
\hline RTV615 Silicone & 4 days & 0.27 years \\
\hline EVA & 0.35 years & 8.8 years \\
\hline BRP-C & 29 years & 738 years \\
\hline Aclar & 1,260 years & 31,600 years \\
\hline
\end{tabular}

Table 1. Time required for the center of a module with impermeable front and back-sheets to reach half of its equilibrium water content using different encapsulants. Data evaluated at $27^{\circ} \mathrm{C}$. 
Table 1 shows the equilibration half-time for moisture ingress into a module with impermeable front- and backsheets. Because the diffusivities of the different materials vary by orders of magnitude, one can also see that the equilibration time for the low-diffusivity materials can be very long. In addition to the high cost of low-diffusivity materials such as Aclar (polychlorotrifluorethylene) (which would keep a module completely dry for the lifetime of a module), there are also problems limiting their use associated with adhesion and with their high modulus. If the material delaminates under environmental exposure, water will enter a module extremely rapidly. One of the purposes of the encapsulant is to provide mechanical support to protect cells from breaking, but the high mechanical moduli of materials such as Aclar make them poor choices for encapsulants.

\section{Edge Seals}

The effectiveness of edge-seal materials were determined by measuring the time required for significant amounts of moisture to begin permeating a membrane (see Fig. 6). This time (the breakthrough time $\tau_{b}$ ) is related to the thickness and diffusivity of a membrane by

$$
\tau_{b}=K \frac{l^{2}}{D}
$$

where $\mathrm{K}$ is a material-dependent constant [4]. Because this is a 1-D diffusion process, similar to the permeation through an edge seal, the breakthrough time for a PV module can be determined by replacing $l^{2}$ with the width of the edge seal (see Table 2).

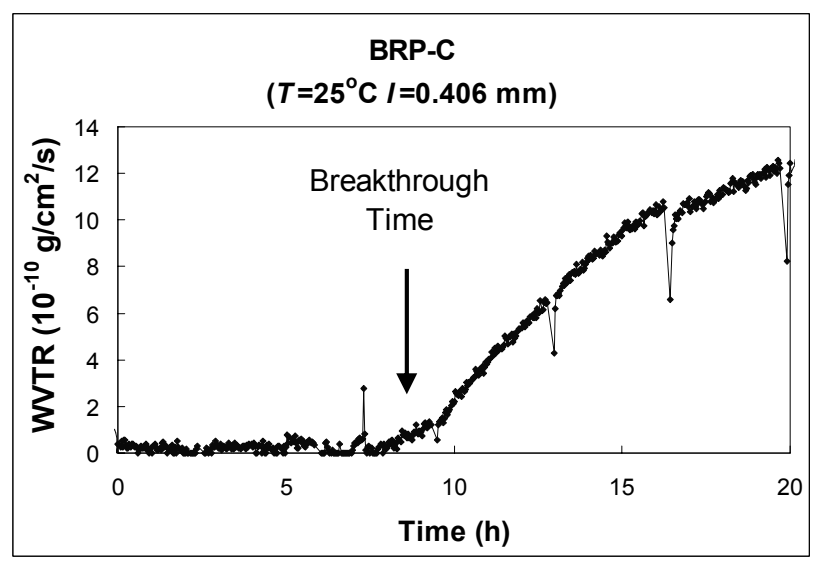

Fig. 6. Transient WVTR profile for the BRP-C material indicating the breakthrough time.

\begin{tabular}{|l|l|l|l||l|}
\hline Material & $\begin{array}{l}\tau_{b} \\
(\mathrm{~min})\end{array}$ & $\begin{array}{l}\text { Membrane } \\
\text { Thickness } \\
l(\mathrm{~mm})\end{array}$ & $\begin{array}{l}\frac{K}{D}=\frac{\tau_{b}}{l^{2}} \\
\left(\mathrm{~min} / \mathrm{mm}^{2}\right)\end{array}$ & $\begin{array}{l}\text { Edge Seal } \\
\begin{array}{l}\text { Break- } \\
\text { through } \\
\text { Time for } \\
l=12.5 \mathrm{~mm}\end{array}\end{array}$ \\
\hline $\begin{array}{l}\text { RTV615 } \\
\text { PDMS }\end{array}$ & 4.67 & 3.25 & 0.442 & $1.15 \mathrm{~h}$ \\
\hline EVA & 3.6 & 0.457 & 17.2 & 2 days \\
\hline BRP-C & 550 & 0.406 & 3,336 & 362 days \\
\hline Aclar & 35 & 0.0229 & 66,740 & 20.3 yrs \\
\hline
\end{tabular}

Table 2. Determination of break-through times for different edge-seal materials.

The use of Aclar as an edge seal material is precludeed for the same reasons it cannot be used as an encapsulant. The BRP-C material, however, has potential as an edge seal because of its low-diffusivity. Even though its diffusivity is not Fickian, Eq. 6 can still be applied and an edge seal consisting of $12.5 \mathrm{~mm}$ of BRP-C should be able to exclude moisture for a year. If one were to replace the filler material with a desiccant, then the breakthrough time might be increased significantly.

\section{CONCLUSIONS}

Because of the relatively high diffusion rate of water in EVA, even a module with a glass/glass construction will have significant moisture ingress over the lifetime of the module. The only way to prevent moisture ingress is with a true hermetic seal or by using a low-diffusivity edge seal containing a large amount of desiccant. Therefore, if a PV device is very sensitive to moisture, it may be more economical to focus on ways to reduce the corrosion processes that are enhanced by moisture ingress.

\section{REFERENCES}

[1] J. Crank, "The Mathematics of Diffusion," p. 50, Clarendon Press, Oxford (1975).

[2] D. R. Myers, "Service Life Prediction of Organic Coatings, A Systems Approach," Chapter 6, American Chemical Society, Oxford (1999).

[3] M. Tencer, "Moisture Ingress into Nonhermetic Enclosures and Packages," IEEE, 196-208 (1994).

[4] D. R. Paul and D. R. Kemp, "The Diffusion Time Lag in Polymer Membranes Containing Adsorptive Fillers," J.

Polymer Sci.: Symposium No. 41, 79-93 (1973). 


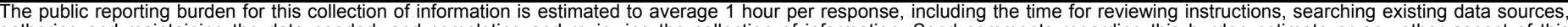

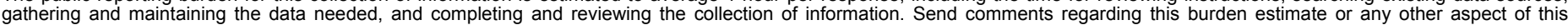

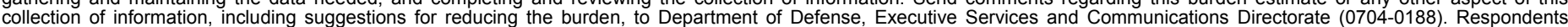

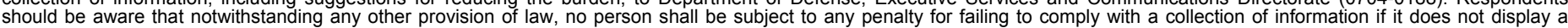

should be aware that notwithstanding

PLEASE DO NOT RETURN YOUR FORM TO THE ABOVE ORGANIZATION.

\section{REPORT DATE (DD-MM-YYYY) \\ February 2005 \\ 2. REPORT TYPE \\ Conference Paper}

4. TITLE AND SUBTITLE

Control of Moisture Ingress into Photovoltaic Modules
3. DATES COVERED (From - To)

3-7 January 2005

5a. CONTRACT NUMBER

DE-AC36-99-GO10337

5b. GRANT NUMBER

5c. PROGRAM ELEMENT NUMBER

5d. PROJECT NUMBER

NREL/CP-520-37390

5e. TASK NUMBER

PVB57201

5f. WORK UNIT NUMBER

7. PERFORMING ORGANIZATION NAME(S) AND ADDRESS(ES)

National Renewable Energy Laboratory

1617 Cole Blvd.

8. PERFORMING ORGANIZATION REPORT NUMBER

Golden, CO 80401-3393

NREL/CP-520-37390

9. SPONSORING/MONITORING AGENCY NAME(S) AND ADDRESS(ES)

10. SPONSOR/MONITOR'S ACRONYM(S) NREL

11. SPONSORING/MONITORING AGENCY REPORT NUMBER

12. DISTRIBUTION AVAILABILITY STATEMENT

National Technical Information Service

U.S. Department of Commerce

5285 Port Royal Road

Springfield, VA 22161

13. SUPPLEMENTARY NOTES

14. ABSTRACT (Maximum 200 Words)

During long-term exposure of photovoltaic modules to environmental stress, the ingress of water into the module is correlated with decreased performance. By using diffusivity measurements for water through encapsulants such as ethylene vinyl acetate (EVA), we have modeled moisture ingress using a finite-element analysis with atmospheric data from various locations such as Miami, Florida. This analysis shows that because of the high diffusivity of EVA, even an impermeable glass back-sheet alone is incapable of preventing significant moisture ingress from the edges for a 20-year lifecycle. This result has led us to investigate ways to protect modules from moisture through the use of different encapsulating chemistries and materials.

15. SUBJECT TERMS

PV; moisture ingress; module; diffusivity measurements; ethylene vinyl acetate (EVA); glass back-sheet;

\begin{tabular}{|c|c|c|}
\hline $\begin{array}{l}\text { a. REPORT } \\
\text { Unclassified }\end{array}$ & $\begin{array}{l}\text { b. ABSTRACT } \\
\text { Unclassified }\end{array}$ & $\begin{array}{l}\text { c. THIS PAGE } \\
\text { Unclassified }\end{array}$ \\
\hline
\end{tabular}

\begin{tabular}{|c|c|}
\hline $\begin{array}{l}\text { 17. LIMITATION } \\
\text { OF ABSTRACT }\end{array}$ & $\begin{array}{l}\text { 18. NUMBER } \\
\text { OF PAGES }\end{array}$ \\
\hline UL & \\
\hline
\end{tabular}

19a. NAME OF RESPONSIBLE PERSON

19b. TELEPHONE NUMBER (Include area code) 